\title{
Abdominal closure reinforcement by using polypropylene mesh functionalized with poly- $\varepsilon$-caprolactone nanofibers and growth factors for prevention of incisional hernia formation
}

This article was published in the following Dove Press journal:

International Journal of Nanomedicine

9 July 2014

Number of times this article has been viewed

\author{
Martin Plencner ${ }^{1,2, *}$ \\ Barbora East ${ }^{3, *}$ \\ Zbyněk Tonar ${ }^{4}$ \\ Martin Otáhal ${ }^{5}$ \\ Eva Prosecká ${ }^{1,2}$ \\ Michala Rampichová ${ }^{2,6}$ \\ Tomáš Krejčí ${ }^{3}$ \\ Andrej Litvinec ${ }^{2,7}$ \\ Matej Buzgo 2,6 \\ Andrea Míčkovál,2,6 \\ Alois Nečas ${ }^{8}$ \\ Jiří Hoch ${ }^{3}$ \\ Evžen Amler 1,2,9
}

'Institute of Biophysics, Second Faculty of Medicine, Charles University in Prague, Prague, ${ }^{2}$ Laboratory of Tissue Engineering, Institute of Experimental Medicine, Academy of Sciences of the Czech Republic, Prague, ${ }^{3}$ Department of Surgery, Second Faculty of Medicine, Charles University in Prague, Prague,

${ }^{4}$ Biomedical Centre, Faculty of Medicine in Pilsen, Charles University in Prague, Pilsen, ${ }^{5}$ Department of Anatomy and Biomechanics, Faculty of Physical Education and Sport, Charles University in Prague, Prague, ${ }^{6}$ University Center for Energy Efficient Buildings, Czech Technical University in Prague, Buštěhrad, ${ }^{7}$ Department of Breeding and Zoohygiene of Laboratory Animals, Institute of Physiology, Academy of Sciences of the Czech Republic, Prague, ${ }^{8}$ Department of Surgery and Orthopedics, Small Animal Clinic, Faculty of Veterinary Medicine, University of Veterinary and Pharmaceutical Science Brno, Central

European Institute of Technology, Brno, ${ }^{9}$ Faculty of Biomedical Engineering, Czech Technical University in Prague, Kladno, Czech Republic

*These authors contributed equally to this work

Correspondence: Martin Plencner Institute of Experimental Medicine, Academy of Sciences of the Czech Republic, 1083 Vídeňská, Prague 142 40, Czech Republic

Tel +420296442387

Fax +420 296442387

Email martin.plencner@gmail.com
Abstract: Incisional hernia affects up to $20 \%$ of patients after abdominal surgery. Unlike other types of hernia, its prognosis is poor, and patients suffer from recurrence within 10 years of the operation. Currently used hernia-repair meshes do not guarantee success, but only extend the recurrence-free period by about 5 years. Most of them are nonresorbable, and these implants can lead to many complications that are in some cases life-threatening. Electrospun nanofibers of various polymers have been used as tissue scaffolds and have been explored extensively in the last decade, due to their low cost and good biocompatibility. Their architecture mimics the natural extracellular matrix. We tested a biodegradable polyester poly- $\varepsilon$-caprolactone in the form of nanofibers as a scaffold for fascia healing in an abdominal closure-reinforcement model for prevention of incisional hernia formation. Both in vitro tests and an experiment on a rabbit model showed promising results.

Keywords: nanofibers, growth factors, surgical mesh, hernia regeneration, in vivo

\section{Introduction}

Incisional hernia is the most common postoperative complication following abdominal surgery, affecting up to $20 \%$ of patients after midline incision, with 10 -year recurrence rates exceeding $60 \% .^{1,2}$ Unlike in surgical repair of inguinal hernia, there are many solutions and none of them is ideal. ${ }^{3}$ Repair of a large incisional defect often requires the use of an allogeneic, and in some cases even a xenogeneic implant. This can expose the patient to various long-term complications, ie, adhesion formation, graft infection/rejection, fistula formation, and hernia recurrence. ${ }^{4-7}$ At the present time, more than 100 surgical meshes are available on the market. ${ }^{8}$ However, the ideal mesh does not yet exist, and still needs to be developed.

Clearly, the optimal and most suitable material for manufacturing a biological implant has to be biocompatible, should not cause a major inflammatory response, should not show any adverse immune response or cytotoxicity, and should be easily sterilizable without changing its properties. The mechanical properties of the selected material in hernia repair are also important. The ideal mesh should withstand the implantation process and also the patient's postoperative activities. In addition, the optimal mesh should minimize complications connected with the wound-healing process. This process consists of five overlapping stages: hemostasis, inflammation, proliferation, contraction, and remodeling., ${ }^{9,10}$

Implanting a material into a living body can be considered an injury, and likewise evokes a cascade of host reactions, including blood-material interactions with the 
formation of a fibrin matrix, inflammation, cellular infiltration, new tissue formation, and remodeling. After the initial inflammatory response, blood vessels and mesenchymal cells will start to approach and eventually invade the implant. The kind of tissue that is finally formed depends on the microenvironment that the migrated cells will be exposed to. ${ }^{11,12}$

Synthetic material implementation has become the standard for care in the repair of ventral hernias. Numerous synthetic surgical meshes have been designed for use in hernia-repair procedures. However, no single mesh has yet demonstrated the ability to promote reliably both hosttissue remodeling and high-strength repair of abdominal wall defects. Unresorbable synthetic meshes are made of polypropylene (PP; Prolene ${ }^{\circledR}$ [Johnson \& Johnson, New Brunswick, NJ, USA], Marlex ${ }^{\circledR}$ [Phillips 66, Houston, TX, USA], Vypro ${ }^{\circledR}$ [Johnson \& Johnson], ProLite ${ }^{\text {TM }}$ [Maquet, Rastatt, Germany]), polyesters (Dacron ${ }^{\circledR}$ [DuPont, Wilmington, DE, USA], Mersilene ${ }^{\circledR}$ [Johnson \& Johnson]) and expanded polytetrafluoroethylene (Gore-Tex ${ }^{\circledR}$; Newark, DE, USA). Among these types of meshes, the most widely used synthetics for hernia repair worldwide are PP-based materials. Absorbable synthetic prostheses, including glycolic acid (Vicryl ${ }^{\circledR}$; Johnson \& Johnson), polyglycolic acid (Dexon), and carboxycellulose, are generally reserved for temporary abdominal closure, or are used in conjunction with permanent synthetics. ${ }^{8}$ In addition to these, alternative methods of different surgical mesh classification are used worldwide. ${ }^{13,14}$

In living systems, the extracellular matrix (ECM) plays a pivotal role in controlling cell behavior, such as adhesion, proliferation, migration, and differentiation. ${ }^{15}$ Optimal scaffolds designed in tissue engineering should mimic natural ECM. Such a scaffold would create the finest microenvironment for cell adhesion and proliferation. Clearly, nanofibrous scaffolds meet these requirements not only due to their topography but also due to their high surface-to-volume ratio and the possibility to modify their surface and interior to improve biocompatibility. ${ }^{16,17}$ In recent years, the electrospinning method has been applied for this purpose, as it is a simple and cost-effective way to fabricate fibers both from synthetic polymers and from other substances. ${ }^{18}$ The topographical features of the fibers can easily be adjusted to fit specific applications by controlling various parameters. ${ }^{18-20}$

The polyesters of the poly( $\alpha$-hydroxy acid) family are significant bioresorbable materials used in biomedical applications. Poly- $\varepsilon$-caprolactone (PCL) has frequently been chosen for electrospinning, because it is a US Food and Drug Administration-approved, biocompatible, and biodegradable semicrystalline aliphatic polyester. PCL has been shown to support the attachment and growth of chondrocytes, ${ }^{21}$ osteoblasts, ${ }^{22,23}$ smooth-muscle cells (SMCs), ${ }^{24}$ fibroblasts, ${ }^{22,25,26}$ myoblasts,${ }^{27}$ and mesenchymal stem cells. ${ }^{28}$

In a recent study, we developed a composite nanofiber-PP mesh. The purpose of this study was to evaluate the potential benefit of the PCL nanofiber mesh in vitro and in vivo in hernia surgery. Additionally, in order to support cell adhesion and growth after implantation, PCL nanofibers were further functionalized by adsorption of growth factors (GFs). Biomechanical support for a PP mesh in combination with the ECM-mimicking structure of PCL nanofibers could lead to improved healing outcomes.

\section{Materials and methods Preparation of the meshes and scaffolds}

PCL nanofibers were prepared by an electrospinning method from PCL with a molecular weight of 45,000 (SigmaAldrich, St Louis, MO, USA). ${ }^{18}$ Electrospinning was performed from a $14 \mathrm{wt} \%$ solution of PCL dissolved in chloroform:ethanol with a ratio of 8:2. A high-voltage source generated voltages of up to $50 \mathrm{kV}$, and the polymer solution was connected to a high-voltage source. Electrospun nanofibers were deposited on the grounded collecting electrode. The PP surgical mesh (Prolene) was coated with PCL nanofibers. Prolene was attached to the grounded collecting electrode, and the PCL nanofibers were deposited on the mesh from both sides.

For in vitro tests, Prolene and Prolene coated with PCL nanofibers were cut into round patches $6 \mathrm{~mm}$ in diameter and sterilized using ethylene oxide at $37^{\circ} \mathrm{C}$. For in vivo tests, PCL nanofibers, Prolene, and Prolene coated with PCL nanofibers were cut into rectangular shapes with $4 \mathrm{~cm}$ and $8 \mathrm{~cm}$ sides. The scaffolds were sterilized using ethylene oxide at $37^{\circ} \mathrm{C}$. The GFs were bound to the scaffold by 12 hours' incubation in a phosphate-buffered saline (PBS; pH 7.4) solution, which contained 200 ng/mL IGF-I [IGF-1, human recombinant (hr) (Sigma-Aldrich), $40 \mathrm{ng} / \mathrm{mL}$ basic FGF (bFGF; hr; Hoffman-La Roche, Basel Switzerland), and $4 \mathrm{ng} / \mathrm{mL}$ TGF- $\beta_{2}$ from porcine platelets (Sigma-Aldrich). After incubation, GFs were adhered on the surface of nanofibers. The release of GFs from nanofibers was in the order of 1-3 weeks. ${ }^{29}$ Implanted scaffolds without the GF were incubated in PBS ( $\mathrm{pH}$ 7.4) for 12 hours. 


\section{In vitro analysis}

Scanning electron microscopy and stereological analysis of native meshes and scaffolds

Nanofibers were sputter-coated with a layer of gold approximately $60 \mathrm{~nm}$ in thickness using a Polaron sputter coater (SC510; Quorum Technologies, East Grinstead, UK). The samples were examined in an Aquasem (Tescan, Brno, Czech Republic) scanning electron microscope (SEM) in secondary electron mode at $15 \mathrm{kV}$.

The electrospun scaffolds were characterized in terms of fiber diameter and pore size using mathematical stereological methods, as described in detail in Mickova et al. ${ }^{30}$ Briefly, the stereological parameters were measured from arbitrarily selected sections of the SEM images, using Ellipse software (version 2001; ViDiTo, Košice, Slovakia). The distribution of the fiber diameters and pore sizes were determined quantitatively from 200 measurements.

\section{Cell cultivation and seeding}

The mouse 3 T3 fibroblast cells (line 3T3-Swiss albino CCL-92 ${ }^{\mathrm{TM}}$; American Type Culture Collection, Manassas, VA, USA) were routinely maintained in a humidified incubator with an atmosphere of $5 \% \mathrm{CO}_{2}$ in air at $37^{\circ} \mathrm{C}$ with fresh medium changed every 2 days. The cells were cultured in Dulbecco's Modified Eagle's Medium (Pan-Biotech, Aidenbach, Germany) supplemented with 10\% fetal bovine serum (PAA Laboratories, Pasching, Austria) and penicillin-streptomycin (100 IU/mL and $100 \mu \mathrm{g} / \mathrm{mL}$, respectively; Sigma-Aldrich). When the cells reached $80 \%-90 \%$ confluence, they were suspended using trypsin-ethylenediaminetetraacetic acid (PAA Laboratories). For detection of metabolic activity, the scaffolds were seeded with $3 \mathrm{~T} 3$ fibroblasts at a density of $3 \times 10^{3}$ cells $/ \mathrm{cm}^{2}$.

\section{Metabolic activity of fibroblasts cultivated on the surface of meshes and scaffolds}

MTT (3-[4,5-dimethylthiazol-2-yl]-2,5-diphenyltetrazolium bromide, $50 \mu \mathrm{L}, 1 \mathrm{mg} / \mathrm{mL}$; Sigma-Aldrich) in PBS ( $\mathrm{pH} 7.4$ ) were added to $150 \mu \mathrm{L}$ of the sample medium and incubated for 4 hours at $37^{\circ} \mathrm{C}$. Using mitochondrial dehydrogenase of normally metabolizing cells, the MTT was reduced to purple formazan. Formazan crystals were solubilized with $100 \mu \mathrm{L}$ of $50 \% \mathrm{~N}, \mathrm{~N}$-dimethylformamide in $20 \%$ sodium dodecyl sulfate at $\mathrm{pH} 4.7$. The results were examined by spectrophotometry in an enzyme-linked immunosorbent assay reader (EL 800; BioTek, Winooski,
VT, USA) at $570 \mathrm{~nm}$ (reference wavelength $690 \mathrm{~nm}$ ). The metabolic activity of 3T3 fibroblasts on a scaffold was tested on days $1,3,7$, and 10 .

\section{In vivo study}

\section{Animal model, study groups, and animal care}

A total of 27 rabbits were randomly divided into six groups. In group I (the control group), the tissue defect in the fascia was primarily closed using a 4/0 PP suture. In groups II, III, and $\mathrm{V}$, the defect in the fascia was closed with a 4/0 PP suture, and a $4 \times 8 \mathrm{~cm}$ mesh was placed over the fascia in an onlay position, overlapping the incision by $2 \mathrm{~cm}$ circumferentially. Group II was treated with a Prolene mesh only (the second control group), while group III was treated with a Prolene mesh functionalized with PCL nanofibers enriched with GF, and group V was treated with a Prolene mesh functionalized with PCL nanofibers without GF. The mesh was then fixed with a continuous suture technique, using a 4/0 PP suture. The last continuous stitch was used to suture the mesh to the incision line. Groups IV and VI were treated with PCL nanofibers only, with adhered GF (group IV) or without GF (group VI). For better understanding, the groups are summarized in Table 1.

Twenty seven Chinchilla rabbits $(3.2 \pm 0.3 \mathrm{~kg}), 4$ months old, were obtained from a conventional breed (CB Bio, Prague, Czech Republic) and bred in standard cages without bedding. The rabbits were fed ad libitum using the standard granular diet for rabbits (TM-MaK 1; Akvaristika Bergman, Karlovy Vary, Czech Republic). Ethical principles and guidelines for scientific experiments on animals were respected throughout this study. The maintenance and handling of the experimental animals followed EU Council Directive 86/609 EEC, and the animals were treated in accordance with the principles of care and use of animals. The investigation was approved by the Expert Committee of the Institute of Physiology, Academy of Sciences, Prague, Czech Republic, and conformed to Czech Animal Protection Law 246/92.

Table I Groups and meshes used

\begin{tabular}{ll}
\hline Group & Mesh \\
\hline I & Suture only \\
II & PP \\
III & PP + PCL nanofibers + growth factors \\
IV & PCL nanofibers + growth factors \\
V & PP + PCL nanofibers \\
VI & PCL nanofibers \\
\hline
\end{tabular}

Abbreviations: PP, polypropylene; PCL, poly- $\varepsilon$-caprw olactone. 


\section{Surgical procedure, killing, and sample collection}

The animals were premedicated with intramuscular $15 \mathrm{mg}$ diazepam pro toto (posterior thigh: semitendinosus and semimembranosus muscles). The surgical procedure was conducted under general anesthesia using ketamine $(35 \mathrm{mg} / \mathrm{kg})$ and xylazine $(3 \mathrm{mg} / \mathrm{kg})$ and subsequent inhalation of $\mathrm{O}_{2}+1.5 \%-2.0 \%$ halothane during surgery. Following completion of all the preoperative preparations, a skin incision of about $6 \mathrm{~cm}$ was cut through the midline of the abdomen, starting $3 \mathrm{~cm}$ below the xiphoid. Another $5 \mathrm{~cm}$-long midline incision was made in the fascia as an abdominal closure model. Antibiotics $(20 \mathrm{mg} / \mathrm{kg} /$ day subcutaneously of cefalexinum monohydricum [cefalexin] for veterinary use) and analgesics $(0.1 \mathrm{mg} / \mathrm{kg} / \mathrm{day}$ subcutaneously of butorphanol tartrate for veterinary use) were administered during the first 3 days. The rabbits were not limited in their movement after surgery. The animals were killed using T61 (Merck, Whitehouse Station, NJ, USA) 6 weeks later. Samples for histological and immunohistochemical analysis were fixed in $10 \%$ phosphatebuffered formalin for 48 hours. Two samples of $1 \times 6 \mathrm{~cm}$ of full-layer abdominal wall with mesh were removed for biomechanical testing (Figure 1), and two samples from the suture line and two from the edge of the mesh were harvested for histological testing. All suturing material was explanted prior to all tests.

\section{Video-recorded biomechanical assay (tensile strength)}

The hysteresis curve and maximum tensile strength were determined on a MicroTester digital tension meter (Device was developed in Department of Anatomy and Biomechanics, Faculty of Physical Education and Sport, Charles University in Prague, Utility model with document/registration number 25008, Industrial Property Office, Czech Republic).
The structure of each sample was scanned throughout the experiment by an SZX-12 microscope (Olympus, Tokyo, Japan) equipped with an ultrasensitive SensiCam video camera (PCO, Kelheim, Germany). The force response of each sample was detected at the branches of the tension meters during the whole cycle. Both static and dynamic properties of each of the samples were analyzed. The following quantities were measured: elasticity in traction $\mathrm{E}\left(\mathrm{N} / \mathrm{mm}^{2}\right)$, maximum strength force $\sigma_{\max }$ per square unit $\left(\mathrm{N} / \mathrm{mm}^{2}\right)$, and the corresponding proportional elongation value $\varepsilon_{\max }$. The localization and the character of the tear line were also analyzed. The tissue samples $(1 \times 6 \mathrm{~cm}$ strips of regenerated abdominal wall) were individually attached to the branches of the tension meter in a longitudinal manner, not including the place covered with scaffolds of a particular type (Figure 2). The samples were stretched by $5 \mathrm{~mm}$ at a speed of $10 \mathrm{~mm} / \mathrm{second}$ ten times, and were then pulled at a speed of $0.5 \mathrm{~mm} / \mathrm{second}$ until the sample broke (Figure 3).

\section{Histological evaluation}

The tissue samples were fixed with buffered formalin, dehydrated, and embedded in paraffin blocks. Six serial histological sections $5 \mu \mathrm{m}$ in thickness were processed from each paraffin-embedded tissue block. $\alpha$-Smooth-muscle actin was used as a marker of the contractile SMC phenotype and myofibroblasts, and CD31 was used as an endothelial marker (Table 2). Endogenous peroxidase activity was blocked with $3 \% \mathrm{H}_{2} \mathrm{O}_{2}$ in PBS. Nonspecific binding activity was blocked with normal goat or horse serum (Table 2) in a phosphate-buffered salt solution at room temperature. The sections were incubated overnight with primary antibodies (Table 2 ) at $4^{\circ} \mathrm{C}$. Immunoreaction products were detected using the immunoperoxidase technique (Table 2), and the reactions were visualized with diaminobenzidine
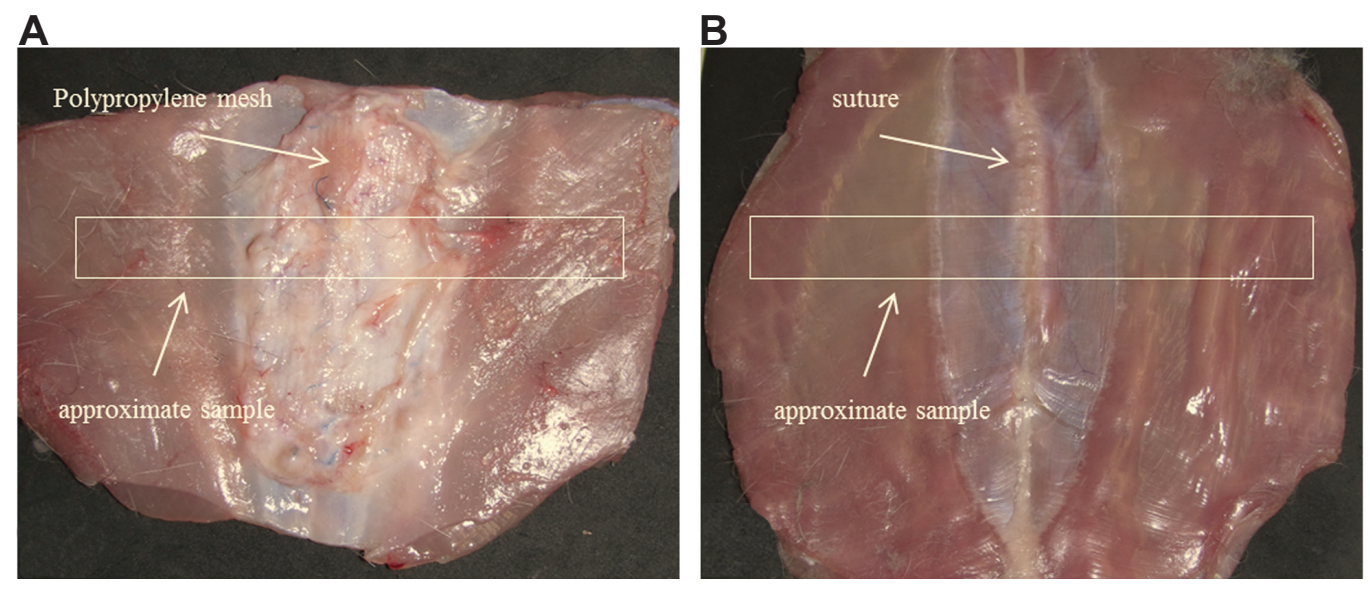

Figure IA, B Full-layer repaired abdominal wall for biomechanical and histological analyses.

Notes: (A) Incision of abdominal wall closed with polypropylene mesh; (B) incision of abdominal wall closed with simple suture. White boxes correspond to the samples of biomechanical analysis. 


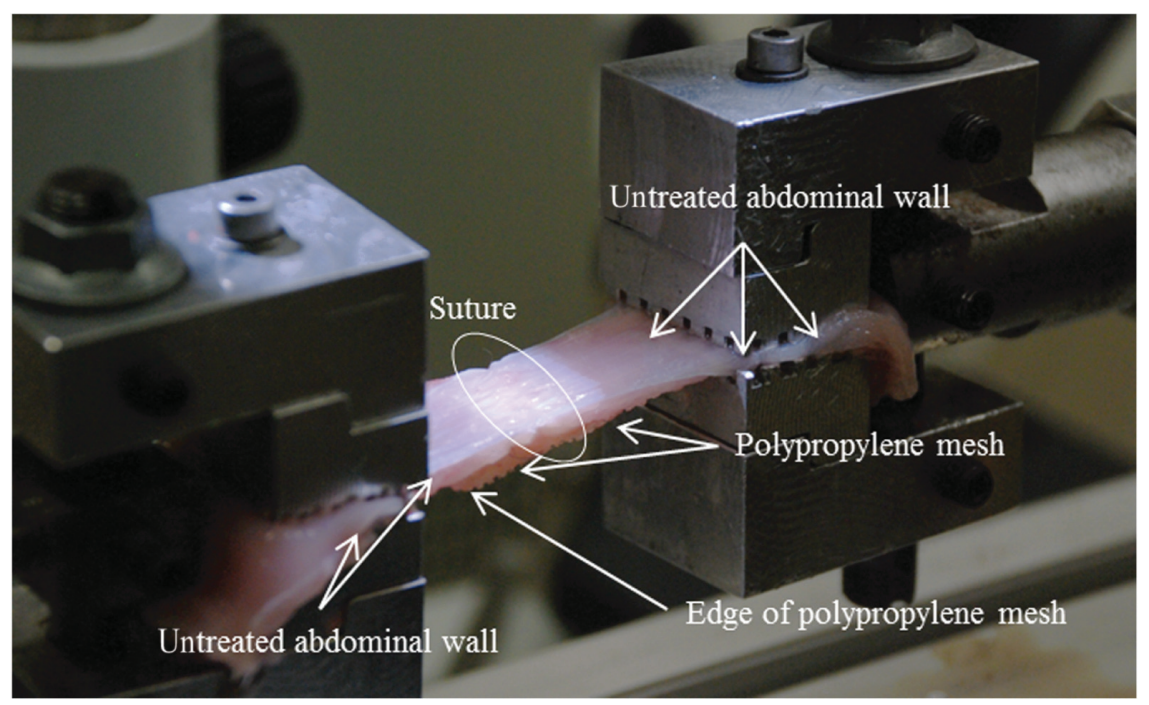

Figure 2 Tensiometer branches with anchored samples during biomechanical analyses.

(Sigma-Aldrich). All sections were counterstained with Gill's hematoxylin. (Dr Kulich Pharma, Otrokovice, Czech Republic). Quantification of area fractions of tissue constituents and quantification of microvessel density were done using the stereological point-counting method and the unbiased counting frame provided by the Ellipse software. ${ }^{31}$

\section{Histological scoring system}

In the literature, there are no references to a method for comparing histological evaluations related to incisional hernia examinations. We suggest a novel scoring system, which is here described in detail.

Two tissue blocks were examined in each animal, one representing the medial region of the abdominal wall with the healing incision, and the other approximately $20 \mathrm{~mm}$ lateral to the median incision. Six serial histological sections $5 \mu \mathrm{m}$ in thickness were processed. Two sections were stained with hematoxylin and eosin (Merck KGaA, Darmstadt, Germany), two sections were stained with Verhoeff's hematoxylin (Merck KGaA) and green trichrome (DiaPath, Martinengo,
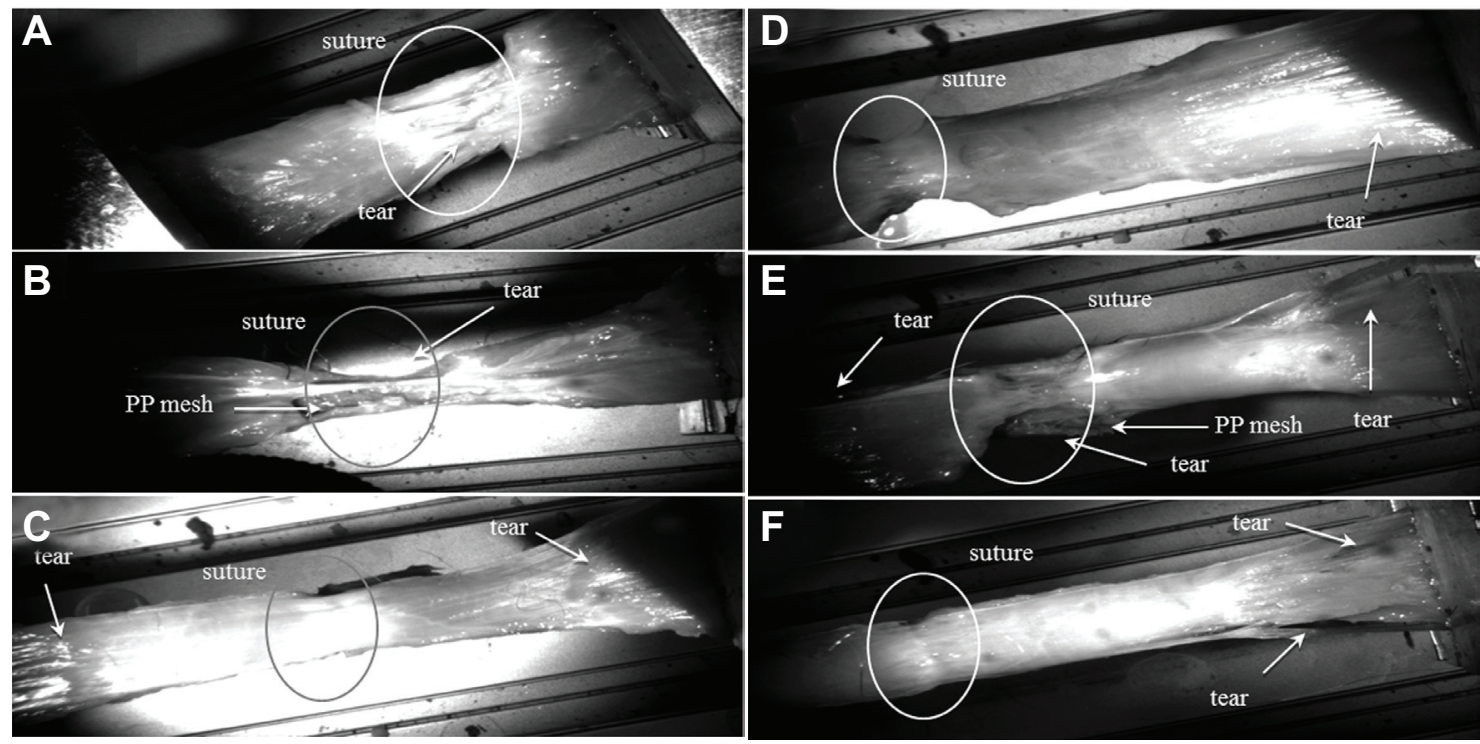

Figure 3A-F Video-recorded biomechanical assay (tensile strength).

Notes: (A) Simple suture tears in the line. (B) Healthy muscle broke at the edge, and the PP mesh slid on the top of the muscle. (C) Tissue treated by a PP mesh functionalized with PCL nanofibers enriched with adhered GF tore at the edge of the mesh and healthy muscle, and the slide was localized between muscle fibers. (D) In some PCL-nanofiber samples with adhered GF, the suture line tore first, but in others a tear occurred between muscle fibers or at the edge of the muscle and the mesh. (E) Healthy muscle tore at the edge, and a PP mesh functionalized with PCL nanofibers slid on top of the muscle, or the tear was localized not between the mesh and the muscle layer but in between muscle fibers. (F) In some PCL-nanofiber samples, the suture line tore first, but in others a tear occurred between muscle fibers or at the edge of the muscle and the mesh. White circles indicate areas of regenerated incision.

Abbreviations: PP, polypropylene; PCL, poly- $\varepsilon$-caprolactone; GF, growth factor. 
Table 2 Primary antibodies used for immunohistochemistry

\begin{tabular}{llll}
\hline Antibody & Blocking serum & Pretreatment & Detection \\
\hline $\begin{array}{l}\text { Monoclonal mouse antihuman smooth-muscle } \\
\text { actin, clone IA4, (Dako, Glostrup, Denmark) }\end{array}$ & $\begin{array}{l}\text { Normal goat serum (Dako) } \\
\text { in PBS at room temperature }\end{array}$ & None & N-Histofine kit (Nichirei \\
$\begin{array}{l}\text { Monoclonal mouse antihuman and antirabbit CD3I, } \\
\text { clone JC/70A (Vector Laboratories, Peterborough, }\end{array}$ & $\begin{array}{l}\text { Normal horse serum } \\
\text { for 20 minutes at room }\end{array}$ & Biosciences, Tokyo, Japan) \\
UK), dilution I:25 (endothelial marker) & temperature & retrieval with Proteinase & ImmPress reagent kit with \\
& & K (Dako) for 6 minutes & peroxidase MP-7402 \\
& & & (Vector Laboratories) \\
\hline
\end{tabular}

Abbreviation: PBS, phosphate-buffered saline.

Italy) to visualize the connective tissue, ${ }^{32}$ and two sections were processed immunohistochemically in order to reveal the presence of microvessels, SMCs, and myofibroblasts. We used $\alpha$-smooth-muscle actin as a marker of the contractile SMC phenotype and myofibroblasts, and CD31 as an endothelial marker, as previously described. All sections were counterstained with Gill's hematoxylin.

We used five continuous variables describing the tissue reaction of the connective tissue below the dermis and super- ficial to the abdominal muscle. The presence of collagen, adipose tissue, and granulomatous infiltrates was assessed in the sections stained with Verhoeff's hematoxylin and green trichrome (Figure 4A). The presence of $\alpha$-smooth-muscle actin and the presence of CD31-positive microvessel profiles were assessed in immunohistochemical sections (Figure 4B and C). Two micrographs for each staining and tissue block were taken in a systematically random manner, using $20 \times$ magnification (quantification of CD31-positive microvessels)
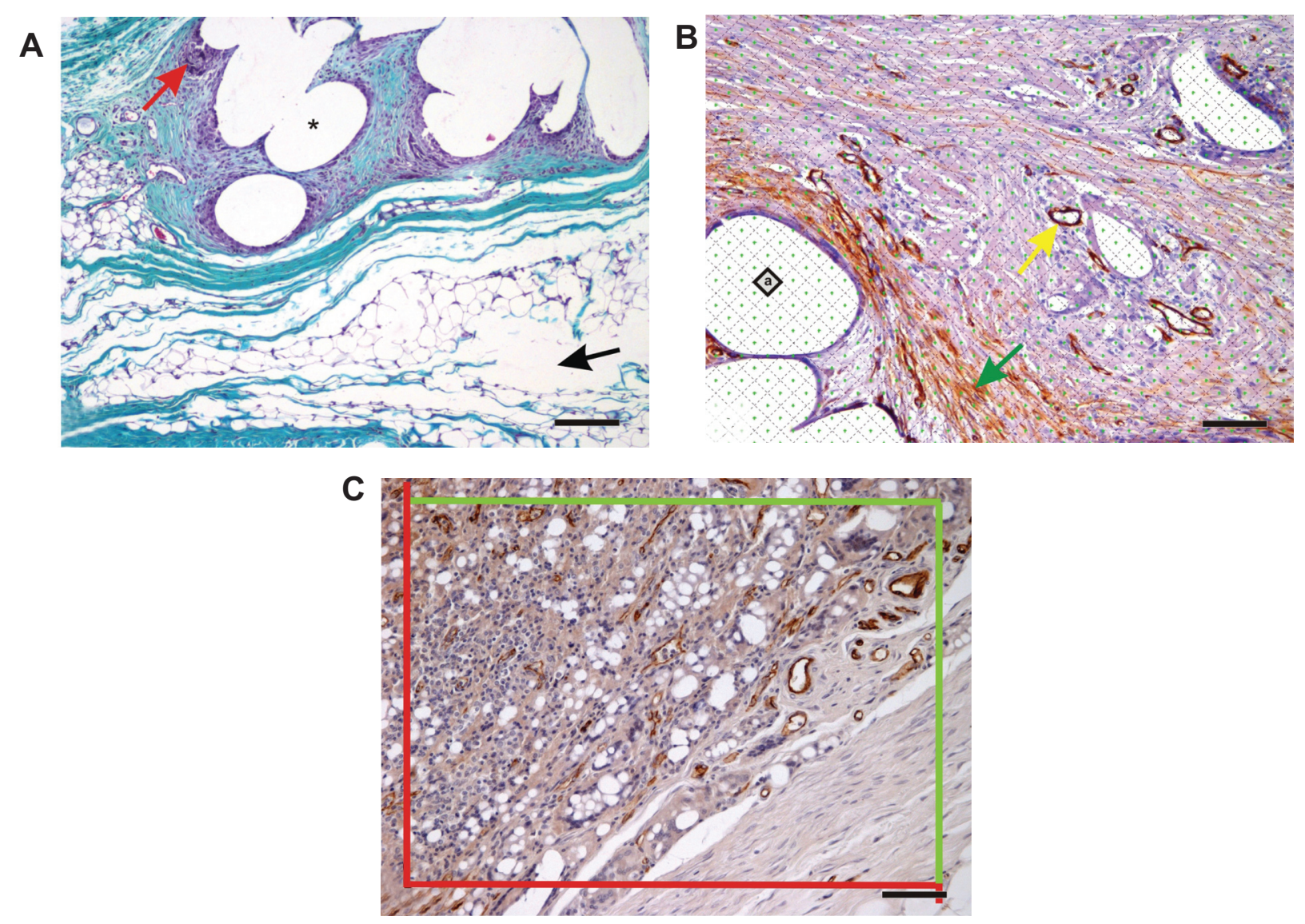

Figure 4A-C Histological quantification.

Notes: (A) In sections stained with Verhoeff's hematoxylin (Merck KGaA, Darmstadt, Germany) and green trichrome (DiaPath, Martinengo, Italy), the area fraction of collagen (stained green), adipose tissue, and granulomatous infiltrates (red arrow) was quantified. The area occupied by dissolved tissue scaffolds (asterisk) or by artificial microcracks (black arrow) was excluded from the reference area. Magnification 100x, scale bar $200 \mu \mathrm{m}$. (B) For all area quantifications, stereological point grids were superimposed on histological micrographs, points striking the structures of interest within the total area were counted, and the sum of these points was multiplied by the area corresponding to each point (marked "a" within the square). This is illustrated in an immunohistochemical section showing $\alpha$-smooth-muscle actin-positive vascular smooth-muscle cells (yellow arrow) and myofibroblasts (green arrow). Magnification 200x, scale bar $100 \mu \mathrm{m}$. (C) Counting CD3I-positive microvessel profiles per section area using projection of an unbiased counting frame consisting of two admittance borders (green) and two forbidden borders (red). Magnification 200×, scale bar I00 $\mu$ m. Counterstaining Gill's hematoxylin (Dr Kulich Pharma, Otrokovice, Czech Republic) (B, C). 
or $10 \times$ magnification (other parameters). Next, a randomly positioned uniform grid of equidistant points was placed on the micrographs in an overlay, so that the number of points striking the collagen, adipose tissue, granulomatous infiltrates, and $\alpha$-smooth-muscle actin-positive cells was proportional to their area. We counted the number of points striking these structures within the area of the abdominal scar. The area of each major tissue component $A$ was calculated by multiplying the number of counted points by the area corresponding to each point. ${ }^{30}$ The presence of each tissue component in the study was then expressed as their area fraction (Aa) within the connective tissue of the scar and abdominal wall. The area not occupied by connective tissue (tissue microcracks, dissolved mesh and surgical stitches, borders of the section) was excluded from the reference area. The sum of the area fraction of collagen, adipose tissue, granulomatous infiltrates, and $\alpha$-smooth-muscle actin represented the main tissue constituents. The remaining fraction of the tissue was occupied mostly by fibroblasts and scattered connective tissue cells, individual skeletal muscle fibers, ground substance of the ECM, immature collagen, and lumina of blood and lymphatic vessels. In sections stained for $\alpha$-smooth-muscle actin and $\mathrm{CD} 31$, we assessed the quantity of microvessels as the number of microvessel profiles per section area (Qa), using an unbiased counting frame. ${ }^{33}$ Although the $\alpha$-smooth-muscle actin did not label the capillaries that were lacking SMCs, we found a strong positive correlation (Spearman's $R=0.91$ ) between microvessels labeled with $\alpha$-smooth muscle actin and CD31-positive microvessels in a pilot study based on 12 tissue samples. Due to a stronger immunohistochemical reaction, we decided to consider the number of $\alpha$-smooth-muscle actin-positive microvessels as an acceptable estimate for the presence of microvessels. In total, the quantification was based on 220 micrographs. An estimate was made of the density of the microvessel profiles, and 117 microvessel profiles per sample were counted on average.

\section{Statistical analysis}

The quantitative histological data were processed using Statistics Base 9 (StatSoft, Tulsa, OK, USA). Spearman rank-order correlations were used as a measure of the statistical relations between the variables, and Kruskal-Wallis analysis of variance was used for testing the equality of the population medians between the groups under study. We used the Wilcoxon matched-pairs test for paired samples of the medial and lateral abdominal wall of the same animals. Values were considered statistically significant for $P<0.05$. Only significant findings and findings close to significant values are reported.

Quantitative data obtained from the in vitro tests and biomechanical assay are presented as means \pm standard deviation. In the MTT assay the average values were determined from four independently prepared samples. The results were evaluated statistically using one-way analysis of variance (ANOVA) and the Student-Newman-Keuls method. Levels of significance were set at 0.001 and 0.05 .

\section{Results \\ In vitro study \\ SEM and stereological analysis of native meshes and scaffolds}

Various types of functionalized scaffolds were examined using an SEM in secondary electron mode: a sample of PCL nanofibers (Figure 5A), a PP mesh (Figure 5B), and a PP mesh functionalized with PCL nanofibers (Figure 5C). SEM showed a randomly oriented nanofiber layer and
A

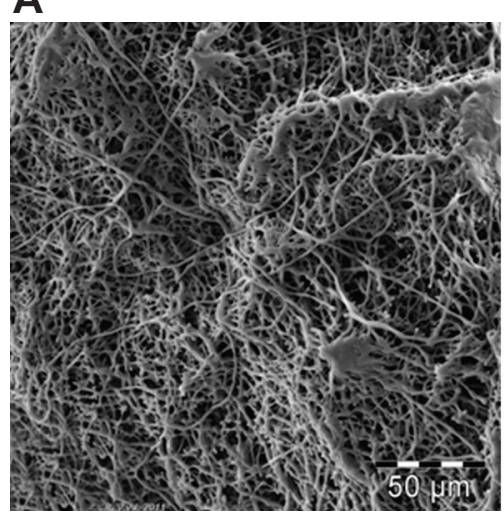

B

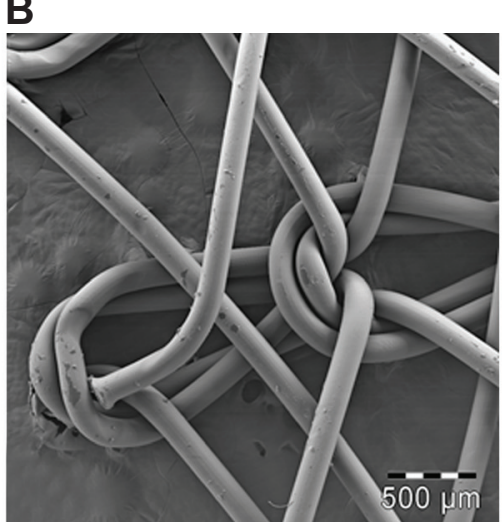

C

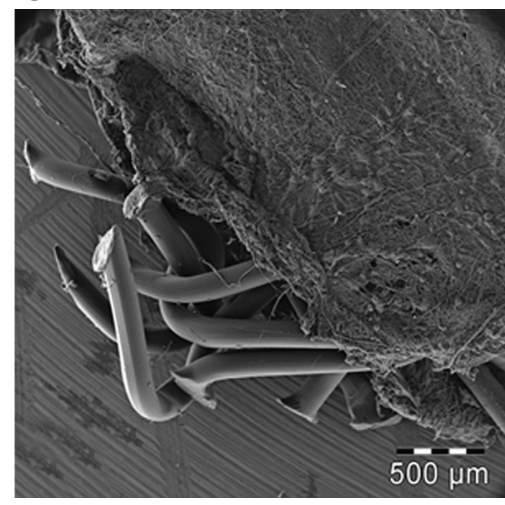

Figure 5A-C Scanning electron microscopy of the implanted scaffolds.

Notes: (A) PCL nanofibers (magnification 230x); (B) PP mesh (magnification 18x); (C) PP mesh functionalized with PCL nanofibers (magnification I8x). Abbreviations: PP, polypropylene; PCL, poly- $\varepsilon$-caprolactone. 
deposition of these nanofibers onto the PP mesh. Stereological analyses showed two fractions of PCL fibers. In one fraction, there were fibers with an average diameter of $1.28 \times 10^{3} \pm 0.33 \times 10^{3} \mathrm{~nm}$, and in the second fraction the average diameter was $466 \pm 170 \mathrm{~nm}$. The average diameter of the PP mesh fibers was about $150 \times 10^{3} \pm 5.4 \times 10^{3} \mathrm{~nm}$.

\section{Metabolic activity of fibroblasts cultivated on the surface of meshes and scaffolds}

The scaffolds were pretested in vitro for preliminary biocompatibility determination. The PP mesh, PP mesh functionalized with PCL nanofibers, PCL nanofibers, and tissue-culture polystyrene were seeded with 3T3 fibroblasts and the cells cultivated for 10 days. An MTT assay was performed on days 1, 3, 7, and 10 to determine the metabolic activity of the cells (Figure 6). We compared the results acquired from days 1, 3, 7, and 10 between cells seeded onto different kinds of scaffolds. The MTT assay showed significantly higher metabolic activity of the cells on days 1, 3, and 7 on the PP mesh functionalized with PCL nanofibers or PCL nanofibers alone than on the simple PP mesh. Additionally, on day 10, the 3 T3 fibroblasts showed metabolic activity at a level of statistical significance of $P<0.001$ on the PCL and PP + PCL scaffolds. The highest metabolic activity of cells was on tissue-culture polystyrene, which was considered to be a positive control.

\section{In vivo study}

\section{Clinical postoperative course}

The animals were killed after 6 weeks. We did not observe any evident changes of condition or weight loss of any animal.
A macroscopic evaluation of samples from all groups was made after explantation of the abdominal wall (Figure 1). The surface of the regenerated tissue showed no signs of inflammation or infection in any groups. The incidence of hernia was not observed in any samples.

\section{Video-recorded biomechanical assay (tensile strength)}

The animals were killed 6 weeks after surgery, and samples of their abdominal walls, including the scar, mesh, and healthy tissue were harvested. Strips of regenerated abdominal wall $(1 \times 6 \mathrm{~cm})$ of each animal (Figure 1), as described in the Materials and methods section, were tested for hysteresis and maximum tensile strength, using the MicroTester digital tension meter (Figure 2). The tissue samples were individually attached to the branches of the tension meter in a longitudinal manner, not including the area covered with scaffolds of a particular type. The samples were stretched by $5 \mathrm{~mm}$ at a speed of $10 \mathrm{~mm} / \mathrm{second}$ ten times, and were then pulled at a speed of $0.5 \mathrm{~mm} /$ seconds until the sample broke (Figure 3 ). The force response of each sample was detected, and both the static and dynamic properties of each of the samples were analyzed. Average values of all measured data are summarized in Table 3.

Values of the variables differed minimally among the groups, because the breach of the tear was almost unconditionally localized at the level of a muscle. The locations of the tear, however, varied significantly among the groups. The suture line broke first if it was not supported by any mesh. Therefore, we have confirmed that

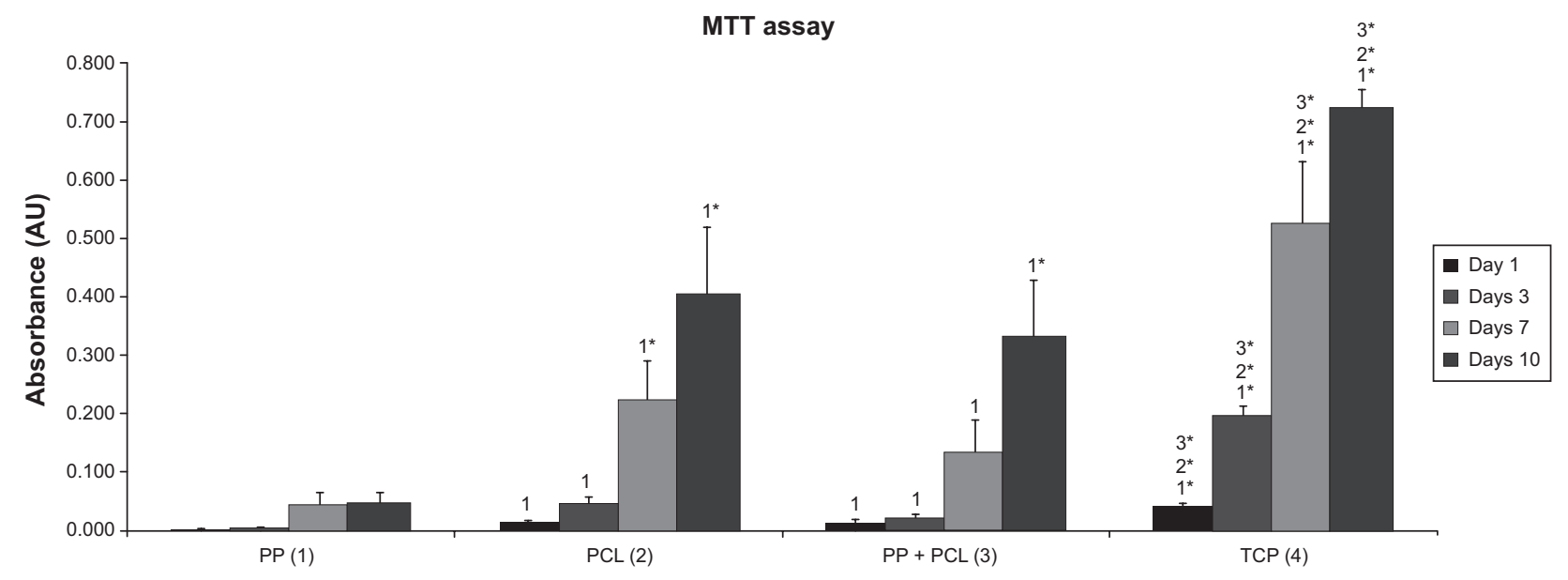

Figure 6 Metabolic activity of 3 T3 fibroblasts cultivated on the surface of PP mesh, PP mesh functionalized with PCL nanofibers (PP + PCL), PCL nanofibers, and TCP. MTT assay revealed significantly higher viability of $3 T 3$ fibroblasts on the PP + PCL and PCL scaffolds on days I, 3, 7, and I0 (indicated by asterisks) compared with scaffolds without functionalization (PP).

Notes: The level of statistical significance for the assays is designated above the mean values $(P<0.05$ indicated by number, $P<0.00 \mathrm{I}$ indicated by number and asterisks). Day I: $2>1 ; 3>1 ; 4>I^{*}, 2^{*}, 3^{*}$. Day 3: $2>1 ; 3>1 ; 4>I^{*}, 2^{*}, 3^{*}$. Day 7: $2>1 * ; 3>1 ; 4>I^{*}, 2^{*}, 3^{*}$. Day $10: 2>I^{*} ; 3^{*}>1 ; 4>I^{*}, 2^{*}, 3^{*}$.

Abbreviations: PP, polypropylene; PCL, poly- $\varepsilon$-caprolactone; TCP, tissue-culture polystyrene; MTT, 3-(4,5-dimethylthiazol-2-yl)-2,5-diphenyltetrazolium bromide. 
Table 3 Average values of the biomechanical quantities

\begin{tabular}{llll}
\hline Group & $\mathbf{E}\left(\mathbf{N} / \mathbf{m m}^{2}\right)$ & $\sigma_{\max }\left(\mathbf{N} / \mathbf{m m}^{2}\right)$ & $\varepsilon_{\max }(-)$ \\
\hline I & $3.73 \pm 1.21$ & $0.50 \pm 0.14$ & $0.30 \pm 0.04$ \\
II & $2.55 \pm 0.75$ & $0.46 \pm 0.07$ & $0.7 I \pm 0.16$ \\
III & $2.73 \pm 0.20$ & $0.61 \pm 0.08$ & $0.6 I \pm 0.06$ \\
IV & $2.60 \pm 1.23$ & $0.64 \pm 0.10$ & $0.6 I \pm 0.15$ \\
V & $2.78 \pm 1.09$ & $0.63 \pm 0.04$ & $0.65 \pm 0.10$ \\
VI & $3.11 \pm 1.43$ & $0.68 \pm 0.08$ & $0.49 \pm 0.08$ \\
\hline
\end{tabular}

Notes: The six experimental groups are presented in the Materials and methods section and in Table I.

Abbreviations: $E$, elasticity in traction or Young modulus in $\mathrm{N} / \mathrm{mm}^{2}(\mathrm{MPa}) ; \sigma$ average values of maximal strength force per square unit in $N / \mathrm{mm}^{2}(\mathrm{MPa}) ; \varepsilon_{\max }$, maximal proportional elongation value.

the suture line is the weakest point of the abdominal wall 6 weeks postsurgery (Figure 3A). In all samples with the PP mesh, the tissue broke first at the edge of the mesh and healthy muscle, followed by a slide of the PP mesh on top of a muscle (Figure 3B, C, and E). The boundary of the mesh and the muscle created a stress concentration, leading to the slip.

In the group with PP functionalized with PCL nanofibers (Figure 3E), two types of tear mechanism were recorded. This was the same as in the PP mesh group, but in some samples the slide was localized not between the mesh and the muscle layer but between the muscle fibers. In the group of PP mesh functionalized with PCL nanofibers enriched with adhered GF (Figure 3C), the tissue also tore at the edge of the mesh and the healthy muscle, and the slide was localized between muscle fibers, with the exception of one sample, where the recorded mechanism was exactly the same as in the PP-mesh group. The PCL nanofibers connected better to the abdominal wall than the PP mesh alone.
In the case of pure PCL nanofibers (Figure 3D and F), various types of tear were observed. In some samples, the suture line tore first. In other samples, a tear occurred between muscle fibers or at the edge of the muscle and the mesh.

Static and dynamic parts of the experiment are documented in Table 3. We compared the average maximal strength force values. All samples functionalized with PCL nanofibers (groups III-VI), with or without adhered GF, showed a significantly increased average maximal strength force $\left(\sigma_{\max }\right)$ compared to a simple PP mesh or suture (groups I and II). Clearly, preserving the elasticity in traction and simultaneously increasing the maximum strength force value indicated a positive effect of nanofibers on fascia healing. Interestingly, PCL nanofibers alone (group VI) showed the highest average maximal strength force value among all samples. Significant differences of average maximal strength force $\left(\sigma_{\max }\right)$ among the experimental groups are presented in Figure 7.

Our results also indicated somewhat more elastic samples in the presence of the PP mesh (groups II-V) compared to samples without the mesh (groups I and VI), as indicated by their slightly lower Young's modulus. A significantly lower elasticity in traction (E) and higher elongation in group IV (PCL nanofibers with GFs) than in group VI (PCL nanofibers without GFs) indicated accelerated fascia regeneration, which can undoubtedly be attributed to the presence of GFs.

\section{Histological evaluation}

The implants were prepared and implanted as described in the Materials and methods section, and were tested in vivo

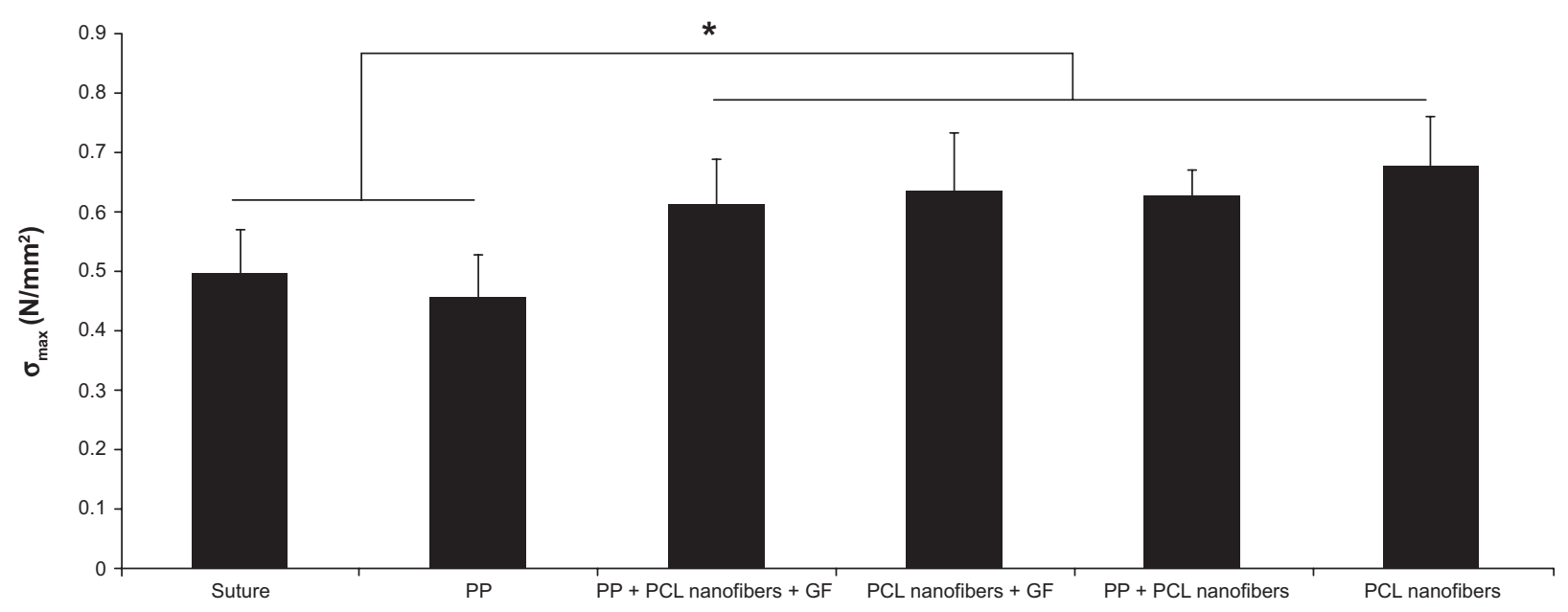

Figure 7 Average values of maximal strength force per square unit in $\mathrm{N} / \mathrm{mm}^{2}(\mathrm{MPa})$ after 6 weeks.

Note: $* P<0.05$.

Abbreviations: $\sigma_{\max }$, average value of maximal strength force per square unit; PP, polypropylene; PCL, poly- $\varepsilon$-caprolactone; GF, growth factor. 
on a small animal model (a rabbit). The animals were killed after 6 weeks. In all groups of scaffolds, there were some differences among the groups in the area fraction occupied by granulomatous infiltrate in medial samples taken from the healing incision, but the difference did not reach statistical significance (Figure 8A). Medial samples with the incision had a higher $\alpha$-smooth-muscle actin fraction $(P=0.003)$, a lower collagen fraction $(P=0.035)$, and a higher density of microvessels $(P<0.001)$ in comparison with samples of the lateral abdominal wall without incision.

A considerable difference was observed in the area occupied by $\alpha$-smooth-muscle actin-positive cells in medial samples of the healing incision (Figure 8B). There were more $\alpha$-smooth-muscle actin-positive cells in all samples containing PCL nanofibers than in the controls (simple suture and PP mesh) (Figure 9). There was no significant difference between the groups containing PCL nanofibers, with the exception of the samples from the lateral portion of the healing incision in PCL-only treated specimens.

Significant differences in the density of the microvessel profiles were observed between the groups in both the medial and the lateral parts of the healing fascia (Figure 8C and D). Samples containing PCL nanofibers had a greater density of microvessel profiles than the control groups (simple suture and PP mesh). The density was clearly highest in the lateral portion of samples with a PP mesh functionalized with PCL nanofibers enriched with adhered GF.

PCL-nanofiber scaffolds showed beneficial properties in fascia healing, and should be further tested in hernia repair application. From the histological point of view, the highest fraction of collagen was observed in samples with PCL nanofibers enriched with adhered GF, followed by samples with no mesh (incision) and by samples functionalized with PCL nanofibers (Figure 10). Samples functionalized with PCL nanofibers and enriched with adhered GF also contained low fractions of adipose tissue (Figure 10). The presence of PCL nanofibers and GF seemed to increase the granulomatous infiltration and vascularization of the healing tissue, because the remnants of nanofibers were surrounded by granulomatous leukocyte-rich connective tissue at the end of week 6 after implantation. Tissue samples with heavier granulomatous infiltration also contained more blood vessels and a higher fraction of vascular smooth muscle and myofibroblasts.

The nonparametric Spearman rank-order correlations between the quantitative histological parameters are listed in Table 4 (for this purpose, the data were pooled across all groups in the study). Tissue samples with heavier granulomatous infiltration contained more blood vessels and a higher fraction of vascular smooth muscle and myofibroblasts at the site of the healing incision.

\section{Discussion}

The main aim of the present study was to develop a composite nanofiber-PP surgical mesh for the prevention of incisional hernia formation. We tested a biodegradable polyester PCL in the form of nanofibers that were deposited onto a PP mesh or implanted independently. Some of the composite scaffolds were further functionalized by adsorption of GFs to support cell adhesion and growth after implantation. Biomechanical support of the PP mesh in combination with the ECM-mimicking structure of PCL nanofibers could lead to improved healing outcomes.

A combination of PCL nanofibers with the most widely used PP surgical mesh (Prolene) was chosen as a suitable material for our study. Jakubova et $\mathrm{al}^{21} \mathrm{Chen}$ et $\mathrm{al}^{26}$ and Rampichová et $\mathrm{al}^{28}$ proved that PCL nanofibers support the attachment and growth of fibroblasts, chondrocytes, and mesenchymal stem cells. In addition, PCL nanofibers as novel absorbable scaffolds for hernia-repair application were biomechanically tested by Ebersole et al. ${ }^{34}$ The authors have shown that electrospun PCL scaffolds retain suture material and possess tensile strength appropriate for hernia repair, and thus have the potential to be a novel class of hernia-repair materials. Our mesh combined good biocompatible properties, environment-promoting cell growth, adherence due to the PCL nanofibers, and tensile strength due to the PP mesh. This study has confirmed that PCL nanofibers promote the proliferation of $3 \mathrm{~T} 3$ fibroblasts. The metabolic activity of cells cultured on a PP mesh functionalized with PCL nanofibers was significantly higher on day 10 than on a simple PP mesh. In addition, adhering various GFs on the surface of our nanofibers increased their regenerative potential. bFGF, IGF-1, and TGF- $\beta_{2}$ may stimulate angiogenesis, fibroblast proliferation, and collagen synthesis, thus enhancing tissue stability. ${ }^{35-37}$ Their concentration ratio and their positive effect on cultivated cells were evaluated in our group by Filová et al. ${ }^{38}$

Ebersole et al and Deeken et al measured the tensile strength and other biomechanical parameters of the prosthetic material used in ventral (incisional) hernia repair without implantation into animal models or human patients. ${ }^{34,39}$ These studies showed that the tensile strength of PCL nanofibers was appropriate for most hernia repairs. Electrospun scaffolds possessing mechanical properties within the predefined range may be suitable for further evaluation in preclinical 
A
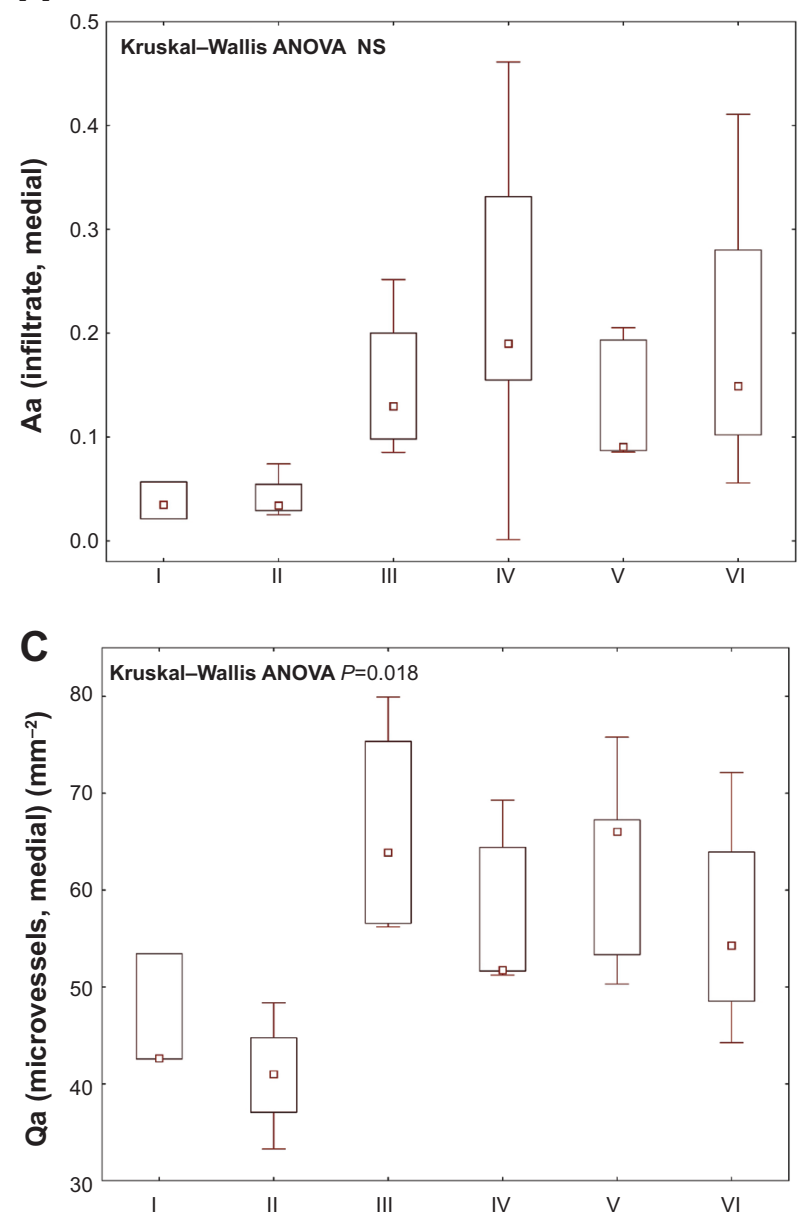

B
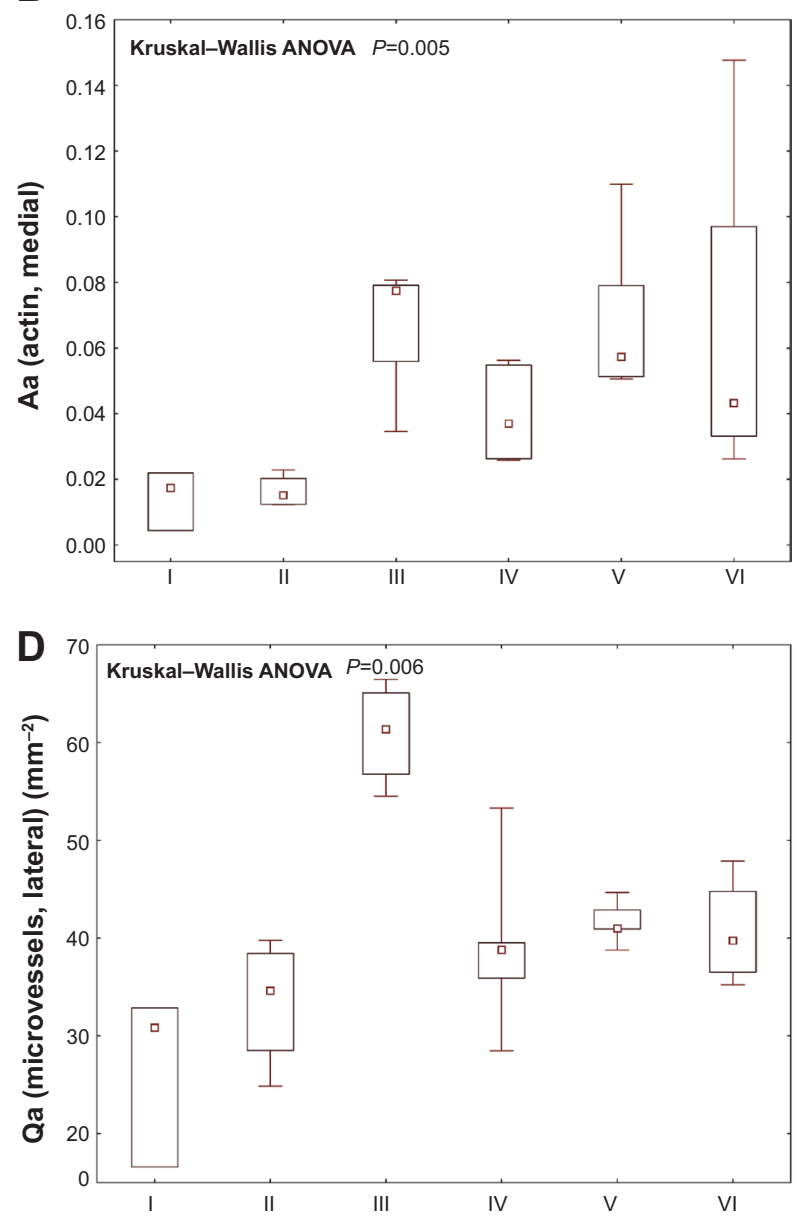

Figure 8A-D Quantitative histological results.

Notes: (A) Inflammatory infiltrate in the medial healing incision in group I (suture only), II (PP mesh), III (PP mesh functionalized with PCL nanofibers enriched with adhered GF), IV (PCL nanofibers enriched with adhered GF), V (PP mesh functionalized with PCL nanofibers), and VI (PCL nanofibers alone). (B) Fraction of $\alpha$-smooth-muscle actinpositive vascular smooth-muscle cells and myofibroblasts in the medial healing incision in groups I-VI. (C) Density of microvessel profiles in medial healing incisions in groups I-VI. (D) Density of microvessel profiles in the abdominal wall $20 \mathrm{~mm}$ lateral from the incision in groups I-VI. Data are presented as medians with boxes spanning the upper limits of the first and third quartiles and with whiskers spanning the minimum and maximum values for each group. $P$-values of Kruskal-Wallis analysis of variance (ANOVA) show differences among groups under study.

Abbreviations: PP, polypropylene; PCL, poly-ع-caprolactone; GF, growth factor; Aa, area fraction; Qa, section area.

trials. ${ }^{39}$ In another study, Melman et al biomechanically tested samples implanted into a porcine model ${ }^{40}$ Samples were attached into the tension meter branches over the entire thickness of the abdominal wall, including the prosthetic material. We suggest a new biomechanical testing method, where the results reflect the real state of the repaired abdominal wall. In our design, the attachment points were adjacent to the implanted mesh, so we tested not only the strength of the implant but also the properties of the mesh-fascia interface and its resistance to distracting forces. We did not test the tensile strength of our samples alone, because the biomechanical parameters of PP meshes are well known..$^{40}$ We modified this prosthetic PP material with PCL nanofibers, and it was thus not necessary to evaluate biomechanical parameters before implantation.
Biomechanical testing at 6 weeks postimplantation showed that the PCL nanofibers improved the biomechanical properties of the healed tissue, as evidenced by a higher average maximal strength force. This applied not only to the nanofibers in combination with a PP mesh, but also to the suture alone. The group treated with suture and PCL nanofibers with or without adhered GFs showed a modulus of elasticity comparable with that of the PP mesh, but higher average maximal strength force. This could reflect lower fibroblast proliferation around the PP mesh, which might be caused by a reduction in the mechanical signals that arise as the structural soft tissue fails. ${ }^{9}$ In addition to these results, video analysis of the biomechanical testing revealed in most cases that if the tissue tore first between the edge of the mesh and healthy tissue, the PP mesh slid off the surface of the muscle. In samples functionalized with PCL 

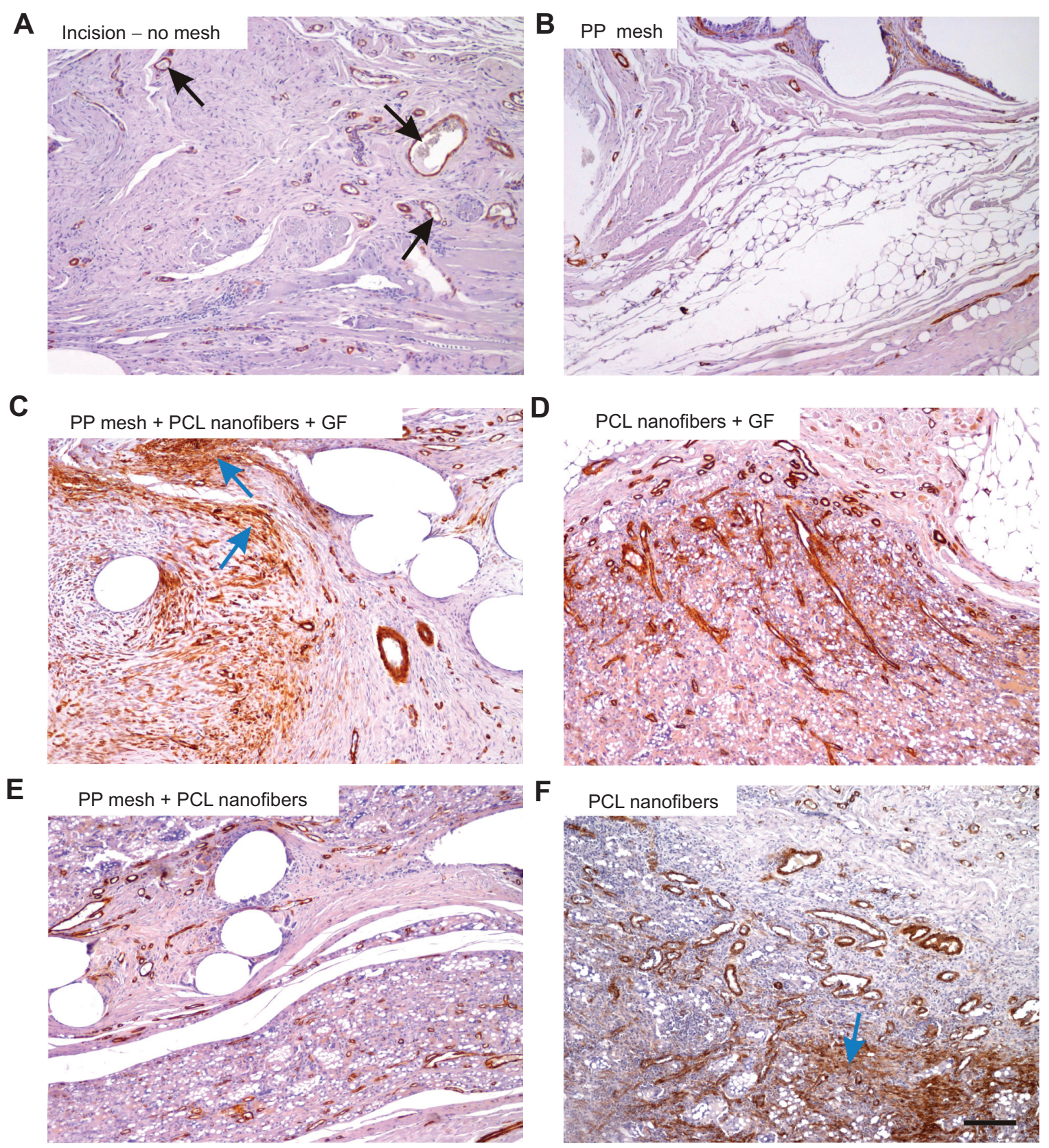

Figure 9A-F $\alpha$-Smooth-muscle positivity in the scaffolds under study.

Notes: The density of the microvessels (some of them pointed out with black arrows) and the area fraction of actin-positive cells (vascular smooth muscle and myofibroblasts, some of the accumulated myofibroblasts highlighted with blue arrows) were highest in the PP mesh samples functionalized with PCL nanofibers enriched with adhered GF (C), followed by the PP mesh functionalized with PCL nanofibers (E), PCL nanofibers (F), and PCL nanofibers enriched with adhered GF (D), while the lowest values were found in samples of pure PP meshes (B) and sham-operated animals with no mesh (A). Immunohistochemistry for $\alpha$-smooth-muscle actin, counterstaining Gill's hematoxylin. Magnification I00X, scale bar $200 \mu \mathrm{m}$.

Abbreviations: PP, polypropylene; PCL, poly- $\varepsilon$-caprolactone; GF, growth factor.

Table 4 Nonparametric Spearman rank-order correlations between the quantitative parameters at the healing incision (medial side)/ without incision (lateral side)

\begin{tabular}{lllll}
\hline & Aa (adipose) & Aa (infiltrate) & Aa (actin) & Qa (microvessel) (mm $\left.\mathbf{~}^{-2}\right)$ \\
\hline Aa (collagen) & $-0.59 /-0.42$ & $-0.46 /-0.50$ & NS/NS & NS/NS \\
Aa (adipose) & - & NS/NS & NS/NS & NS/NS \\
Aa (infiltrate) & - & - & $0.57 / 0.47$ & $0.50 /$ NS \\
Aa (actin) & - & - & - & $0.53 / 0.69$ \\
\hline
\end{tabular}

Notes: Marked correlations were significant at $\mathrm{P}<0.05$. Autocorrelations and repeating values are replaced by en dashes.

Abbreviations: Aa, area fraction; $\mathrm{Qa}$, section area; NS, not significant. 
A

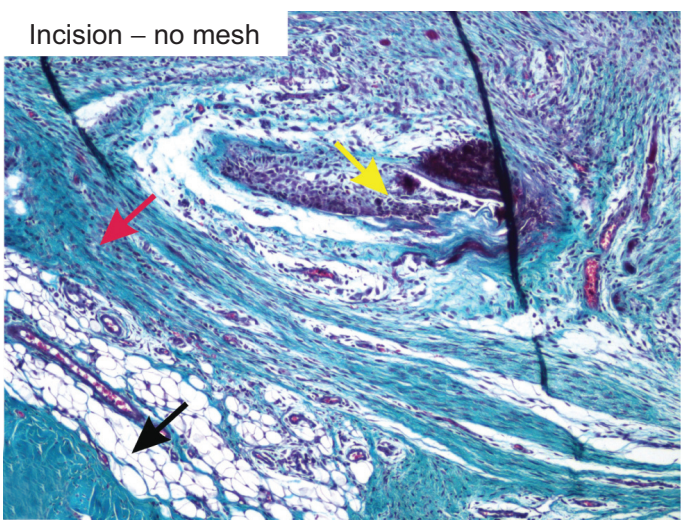

C

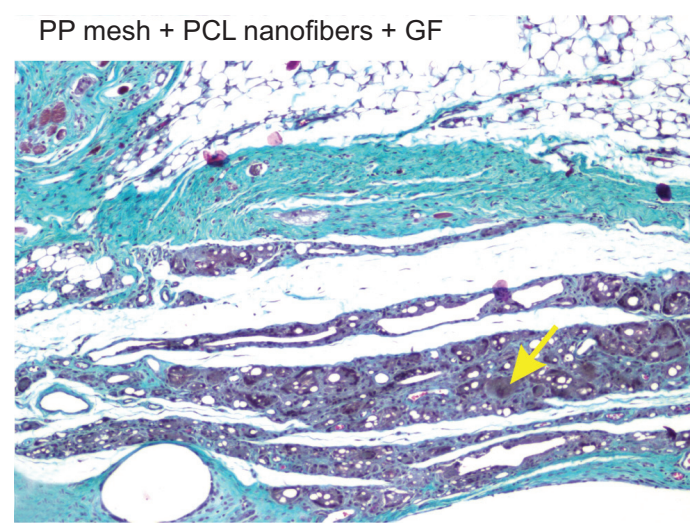

E

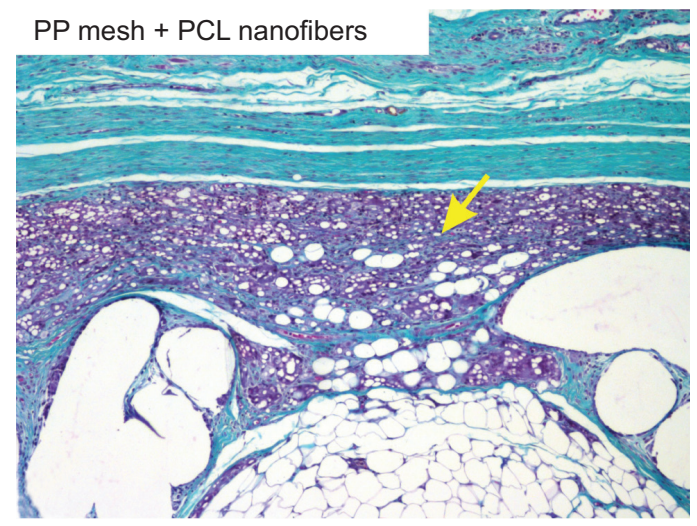

B PP mesh

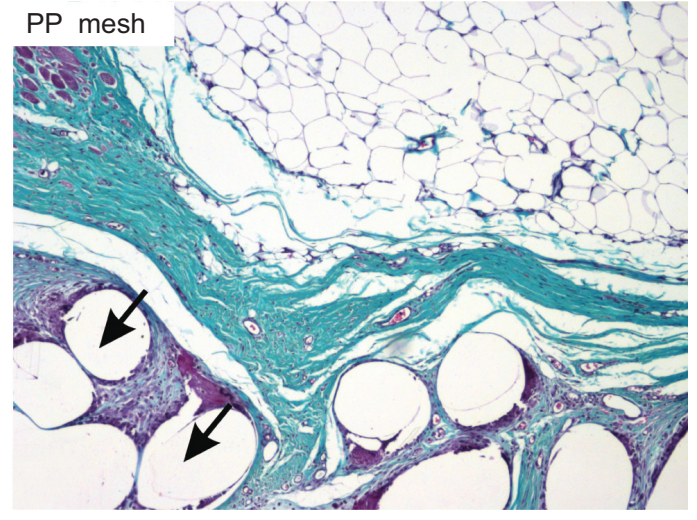

D PCL nanofibers + GF

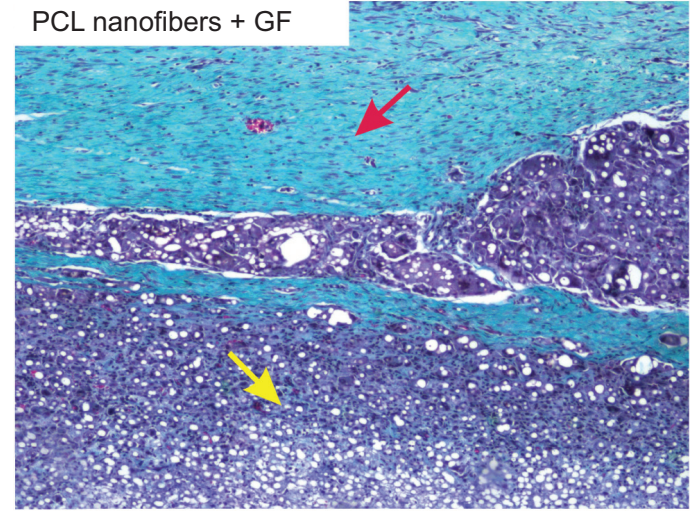

$\mathbf{F}$

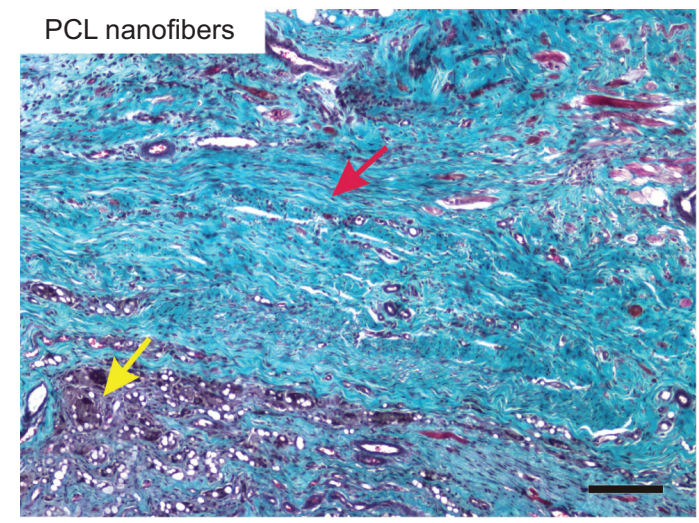

Figure I0A-F Collagen, adipose tissue, and granulomatous infiltration in the scaffolds under study.

Notes: In samples without any mesh (A), the incision was healing with a mixture of collagen (black arrow), adipose connective tissue (red arrow), and inflammatory infiltrate (yellow arrow). Samples with PP mesh (B) had a high fraction of adipose tissue, but the spaces showing the dissolved mesh (black arrows) were surrounded by only a few inflammatory cells. Remnants of the nanofibers $(\mathbf{C}-\mathbf{F})$ were surrounded by granulomatous leukocyte-rich connective tissue (yellow arrows). The highest fraction of collagen (red arrow) was in samples of PCL nanofibers with adhered GF (D), followed by samples with no mesh (A) and by samples of PCL nanofibers (F). Low fractions of adipose tissue were found in samples of PCL nanofibers with adhered GF (D), samples with no mesh (A), and in samples of PCL nanofibers (F). Verhoeffs hematoxylin and green trichrome staining. Magnification I00x, scale bar $200 \mu \mathrm{m}$.

Abbreviations: PP, polypropylene; PCL, poly- $\varepsilon$-caprolactone; GF, growth factor.

nanofibers, we observed two types of tear mechanism. Some were like those in the PP-mesh group, but in other samples the slide was localized between muscle fibers. When the PCL nanofibers were used, different types of tear were observed. In some samples, the suture line tore first, whereas in others a tear occurred between muscle fibers or at the edge of the muscle and the PCL nanofibers. This indicates that PCL nanofibers provide support for fusion of fascia without causing a significant increase in local stiffness, or the formation of a major tension concentrator, as in the case of a PP mesh. Finally, as we had expected, the suture line broke first if it was not supported by any mesh. Therefore, we have confirmed that the suture line is the weakest point of the abdominal wall at 6 weeks postsurgery. 
Prosthetic materials based on PP, which are most widely used, induce a rapid acute inflammatory response followed by a chronic foreign-body reaction. ${ }^{41} \mathrm{We}$ did not observe any significant differences among any groups in the area fraction occupied by granulomatous infiltrate.

The quality of the ECM deposition is dependent among other factors on the content of collagen, which influenced the mechanical properties of the tissue and is notably influenced by the kind of mesh material. ${ }^{42}$ In the examined samples, there were no significant differences among the groups in the area fraction of total collagen. However, the analysis of the main tissue constituents, ie, the collagen fraction, the adipose tissue fraction, and leukocytic infiltration, suggested that the presence of a PP mesh resulted in the formation of a scar with a greater adipose tissue fraction (Figure 10). Tissue samples with heavier granulomatous infiltration also contained more blood vessels and a higher fraction of vascular smooth muscle and myofibroblasts. This finding supports the hypothesis mentioned earlier that there is lower fibroblast proliferation. ${ }^{9}$ Simple sutures contained a large amount of collagen. This supports the hypothesis of tissue flexibility, but these samples also contained a decreased amount of $\alpha$-smooth-muscle actin-positive cells.

There were more $\alpha$-smooth-muscle actin-positive cells in both the medial and lateral parts of samples containing PCL nanofibers than in the other groups. We have proven that nanofibers are a good substrate for cell attachment, and thus they promote cell proliferation and ECM synthesis. In samples with a PP mesh functionalized with PCL nanofibers with adhered GF, there were also more $\alpha$-smooth-muscle actin-positive cells in an area distant from the incision. This could be explained by chemotaxis in this area.

Importantly, our micro/nanofibrous structure showed both mechanical stability of the microfibers and a high surface ratio of nanofibers. A scaffold of this kind has already been reported as acceptable in terms of its biomechanical properties in combination with enhanced cell attachment. ${ }^{43}$ Its structure mimics the ECM, composed of a combination of microfibers and nanofibers. Additionally, due to improved pore size, the scaffold enables efficient cell penetration. A micro/nanofibrous scaffold enabled efficient vascularization in vitro. ${ }^{44}$ We hypothesize that the micro/nanostructure of PCL enables cell penetration and efficient infiltration of blood microvessels.

Thanks to their nanofiber structure, PCL nanofibers provide a better environment for cell growth and proliferation, either in combination with a PP mesh or alone, and are thus a suitable alternative to a standard hernia mesh. Surprisingly, scaffolds with no PP mesh showed even better fascia healing and higher elasticity than a widely used surgical mesh. PCL-nanofiber scaffolds are promising materials for use in hernia repair. By adhering GF into their structure, we can further improve several parameters, especially in the quantity of collagen that is produced compared to the adipose tissue content.

\section{Conclusion}

In conclusion, our experiments have proved a positive effect of PCL nanofibers (submicrofibers) on the biomechanical properties of regenerating fascia. This positive effect was observed both in combination with a PP mesh and when there was a suture alone. In addition, the presence of GFs accelerated tissue regeneration, as was revealed both in biomechanical testing and in histological analysis.

\section{Acknowledgments}

This work was supported by the Academy of Sciences of the Czech Republic (Institutional Research Concept RVO 68378041), the Ministry of Education, Youth and Sports of the Czech Republic (project IPv6), the Grant Agency of Charles University (545313, 384311, 270513, 424213, 648112), and Internal Grant Agency of the Ministry of Health of the Czech Republic (NT12156). Histological quantification was supported by the European Regional Development Fund project ED2.1.00/03.0076, Central European Institute of Technology (CZ.1.05/1.1.00/02.0068), from the European Regional Development Fund. The authors would like to acknowledge O Kofroňová and O Benada from the Laboratory of Molecular Structure Characterization, Institute of Microbiology, Academy of Sciences of the Czech Republic, Prague, Czech Republic, for scanning electron microscopy analyses.

\section{Disclosure}

The authors report no conflicts of interest in this work.

\section{References}

1. Paul A, Korenkov M, Peters S, Köhler L, Fischer S, Troidl H. Unacceptable results of the mayo procedure for repair of abdominal incisional hernias. Eur J Surg. 1998;164:361-367.

2. Burger JW, Luijendijk RW, Hop WC, Halm JA, Verdaasdonk EG, Jeekel J. Long-term follow-up of a randomized controlled trial of suture versus mesh repair of incisional hernia. Ann Surg. 2004;240:578-585.

3. Kingsnorth A. Hernia surgery: from guidelines to clinical practice. Ann $R$ Coll Surg Engl. 2009;91:273-279.

4. Vrijland WW, Bonthuis F, Steyerberg EW, Marquet RL, Jeekel J, Bonjer HJ. Peritoneal adhesions to prosthetic materials: choice of mesh for incisional hernia repair. Surg Endosc. 2000;14:960-963.

5. Jacob BP, Hogle NJ, Durak E, Kim T, Fowler DL. Tissue ingrowth and bowel adhesion formation in an animal comparative study: polypropylene versus Proceed versus Parietex Composite. Surg Endosc. 2007;21: $629-633$. 
6. Losanoff JE, Richman BW, Jones JW. Entero-colocutaneous fistula: a late consequence of polypropylene mesh abdominal wall repair: case report and review of the literature. Hernia. 2002;6:144-147.

7. Jezupors A, Mihelsons M. The analysis of infection after polypropylene mesh repair of abdominal wall hernia. World J Surg. 2006;30: 2270-2278.

8. Shankaran V, Weber DJ, Reed RL, Luchette FA. A review of available prosthetics for ventral hernia repair. Ann Surg. 2011;253:16-26.

9. Franz MG. The biology of hernias and the abdominal wall. Hernia. 2006;10:462-471

10. Binnebösel M, von Trotha KT, Jansen PL, Conze J, Neumann UP, Junge K. Biocompatibility of prosthetic meshes in abdominal surgery. Semin Immunopathol. 2011;33:235-243.

11. Voskerician G, Jin J, White MF, Williams CP, Rosen MJ. Effect of biomaterial design criteria on the performance of surgical meshes for abdominal hernia repair: a pre-clinical evaluation in a chronic rat model. J Mater Sci Mater Med. 2010;21:1989-1995.

12. Cobb WS, Peindl RM, Zerey M, Carbonell AM, Heniford BT. Mesh terminology 101. Hernia. 2009;13:1-6.

13. Klinge U, Klosterhalfen B. Modified classification of surgical meshes for hernia repair based on the analyses of 1,000 explanted meshes. Hernia. 2012;16:251-258.

14. Coda A, Lamberti R, Martorana S. Classification of prosthetics used in hernia repair based on weight and biomaterial. Hernia. 2012;16:9-20.

15. Kim SH, Turnbull J, Guimond S. Extracellular matrix and cell signalling: the dynamic cooperation of integrin, proteoglycan and growth factor receptor. J Endocrinol. 2011;209:139-151.

16. Ma Z, Kotaki M, Inai R, Ramakrishna S. Potential of nanofiber matrix as tissue-engineering scaffolds. Tissue Eng. 2005;11:101-109.

17. Agarwal S, Wendorff JH, Greiner A. Use of electrospinning technique for biomedical applications. Polymer. 2008;49:5603-5621.

18. Lukas D, Sarkar A, Martinova L, et al. Physical principles of electrospinning (electrospinning as a nano-scale technology of the twenty-first century). Text Prog. 2009;41:1-83.

19. Bhardway N, Kundu SC. Electrospinning: a fascinating fiber fabrication technique. Biotechnol Adv. 2010;28:325-347.

20. Grafahrend D, Heffels KH, Beer MV, et al. Degradable polyester scaffolds with controlled surface chemistry combining minimal protein adsorption with specific bioactivation. Nat Mater. 2011;10:67-73.

21. Jakubova R, Mickova A, Buzgo M, et al. Immobilization of thrombocytes on PCL nanofibres enhances chondrocyte proliferation in vitro. Cell Prolif. 2002;44:183-191.

22. Hutmacher DW, Schantz T, Zein I, Ng KW, Teoh SH, Tan KC. Mechanical properties and cell cultural response of polycaprolactone scaffolds designed and fabricated via fused deposition modeling. J Biomed Mater Res. 2001;55:203-216.

23. Kweon H, Yoo MK, Park IK, et al. A novel degradable polycaprolactone networks for tissue engineering. Biomaterials. 2003;24:801-808.

24. Thapa A, Webster TJ, Haberstroh KM. Polymers with nano-dimensional surface features enhance bladder smooth muscle cell adhesion. J Biomed Mater Res A. 2003;67:1374-1383.

25. Venugopal J, Ramakrishna S. Biocompatible nanofiber matrices for the engineering of a dermal substitute for skin regeneration. Tissue Eng. 2005;11:847-854.

26. Chen M, Patra PK, Warner SB, Bhowmick S. Role of fiber diameter in adhesion and proliferation of NIH 3T3 fibroblast on electrospun polycaprolactone scaffolds. Tissue Eng. 2007;13:579-587.

International Journal of Nanomedicine

\section{Publish your work in this journal}

The International Journal of Nanomedicine is an international, peerreviewed journal focusing on the application of nanotechnology in diagnostics, therapeutics, and drug delivery systems throughout the biomedical field. This journal is indexed on PubMed Central, MedLine, CAS, SciSearch $®$, Current Contents $\AA /$ Clinical Medicine,
27. Williamson MR, Adams EF, Coombes AF. Gravity spun polycaprolactone fibres for soft tissue engineering: interaction with fibroblasts and myoblasts in cell culture. Biomaterials. 2006;27:1019-1026.

28. Rampichová M, Chvojka J, Buzgo M, et al. Elastic three-dimensional poly( $\varepsilon$-caprolactone) nanofibre scaffold enhances migration, proliferation and osteogenic differentiation of mesenchymal stem cells. Cell Prolif. 2012;46:23-37.

29. Filová E, Rampichová M, Litvinec A, et al. A cell-free nanofiber composite scaffold regenerated osteochondral defects in miniature pigs. Int J Pharm. 2013;447:139-149.

30. Mickova A, Buzgo M, Benada O, et al. Core/shell nanofibers with embedded liposomes as a drug delivery system. Biomacromolecules. 2012;13:952-962.

31. Mouton PR. Principles and Practices of Unbiased Stereology: An Introduction for Bioscientists. Baltimore: Johns Hopkins University Press; 2002.

32. Kocová J. Overall staining of connective tissue and the muscular layer of vessels. Folia Morphol (Praha). 1970;18:293-295.

33. Gundersen HJ. Estimators of the number of objects per area unbiased by edge effects. Microsc Acta. 1978;81:107-117.

34. Ebersole GC, Buettmann EG, Macewan MR, et al. Development of novel electrospun absorbable polycaprolactone (PCL) scaffolds for hernia repair applications. Surg Endosc. 2012;26:2717-2728.

35. Hunt TK, Knighton DR, Thakral KK, Goodson WH, Andrews WS Studies on inflammation and wound healing: angiogenesis and collagen synthesis stimulated in vivo by resident and activated wound macrophages. Surgery. 1984;96:48-54.

36. Mustoe TA, Pierce GF, Thomason A, Gramates P, Sporn MB, Deuel TF. Accelerated healing of incisional wounds in rats induced by transforming growth factor-beta. Science. 1987;237:1333-1336.

37. Yaeger PC, Masi TL, de Ortiz JL, Binette F, Tubo R, McPherson JM. Synergistic action of transforming growth factor- $\beta$ and insulin-like growth factor-I induces expression of type II collagen and aggrecan genes in adult human articular chondrocytes. Exp Cell Res. 1997;237: 318-325.

38. Filová E, Jelinek F, Handl M, et al. Novel composite hyaluronan/type I collagen/fibrin scaffold enhances repair of osteochondral defect in rabbit knee. J Biomed Mater Res B Appl Biomater. 2008;87:415-424.

39. Deeken CR, Abdo MS, Frisella MM, Matthews BD. Physicomechanical evaluation of absorbable and nonabsorbable barrier composite meshes for laparoscopic ventral hernia repair. Surg Endosc. 2011;25:1541-1552.

40. Melman L, Jenkins ED, Hamilton NA, et al. Histologic and biomechanical evaluation of a novel macroporous polytetrafluoroethylene knit mesh compared to lightweight and heavyweight polypropylene mesh in a porcine model of ventral incisional hernia repair. Hernia. 2011;15: 423-431.

41. Schumpelick V, Klinge U, Junge K, Stumpf M. Incisional abdominal hernia: the open mesh repair. Langenbecks Arch Surg. 2004;389:1-5.

42. Junge $\mathrm{K}$, Klinge U, Klosterhalfen B, et al. Influence of mesh materials on collagen deposition in a rat model. J Invest Surg. 2002;15:319-328.

43. Shalumon KT, Binulal NS, Deepthy M, Jayakumar R, Manzoor K, Nair SV. Preparation, characterization and cell attachment studies of electrospun multi-scale poly(caprolactone) fibrous scaffolds for tissue engineering. J Macromol Sci A. 2011;48:21-30.

44. Santos MI, Tuzlakoglu K, Fuchs S, et al. Endothelial cell colonization and angiogenic potential of combined nano- and micro-fibrous scaffolds for bone tissue engineering. Biomaterials. 2008;29:4306-4313.

\section{Dovepress}

Journal Citation Reports/Science Edition, EMBase, Scopus and the Elsevier Bibliographic databases. The manuscript management system is completely online and includes a very quick and fair peer-review system, which is all easy to use. Visit http://www.dovepress.com/ testimonials.php to read real quotes from published authors. 